these applications were dealt with by the usual grant selection committees of the SRC and only those graded "alpha" were considered for equipment grants. Of these, about 50 per cent were selected for awards.

Now researchers are about to learn if their projects have been judged suitable.

Robin McKie

\section{Investors refuse to back genetic engineering}

Although two major British firms are investing in the industrial application of genetic manipulation techniques, some academics feel the UK is not putting enough money into transferring their research work into industry. The UK has not managed to adopt the US practice of using venture capital to set up small groups of academics and industrialists who develop research to the point where it can be applied to industrial processes. "Investment in the UK is very low", according to Professor K. Murray of Edinburgh University. "Most of the use of genetic manipulation is by small US venture capital groups."

At a meeting on "new horizons in industrial microbiology" at the Royal Society last week, several industrialists responded to these criticisms by saying that venture capital was available but that "research has to pay at some time". The economic climate in the UK meant that many firms did not think it was worth taking the risk of backing a new and uncertain technology. Even if the manufacture of drugs and vaccines by genetic manipulation and, more generally, the production of alternative fuels from organic material by microbiological methods, did become technically feasible, it would be some time before the new processes were economically competitive with current technologies.

A lack of communication between academics and industry was partly to blame for the failure to transfer new ideas. Academics tended to approach industry before their research was sufficiently developed for industry to take advantage of it. Industry, on the other hand, was not willing to take up a promising piece of research where the academics had left off. The result was a gap where good research could fall by the wayside. Dr J D Coombes of Hoechst, UK thought that matters might be improved if academics did not always have to approach the National Research Development Corporation first with their ideas and if they could hold patents.

For the scientists, a major worry was that government spending cuts might affect research. "Staff levels are running down and capital expenditure is down. We will not be able to conserve the strength we already have,' said Professor B S Hartley of Imperial College.

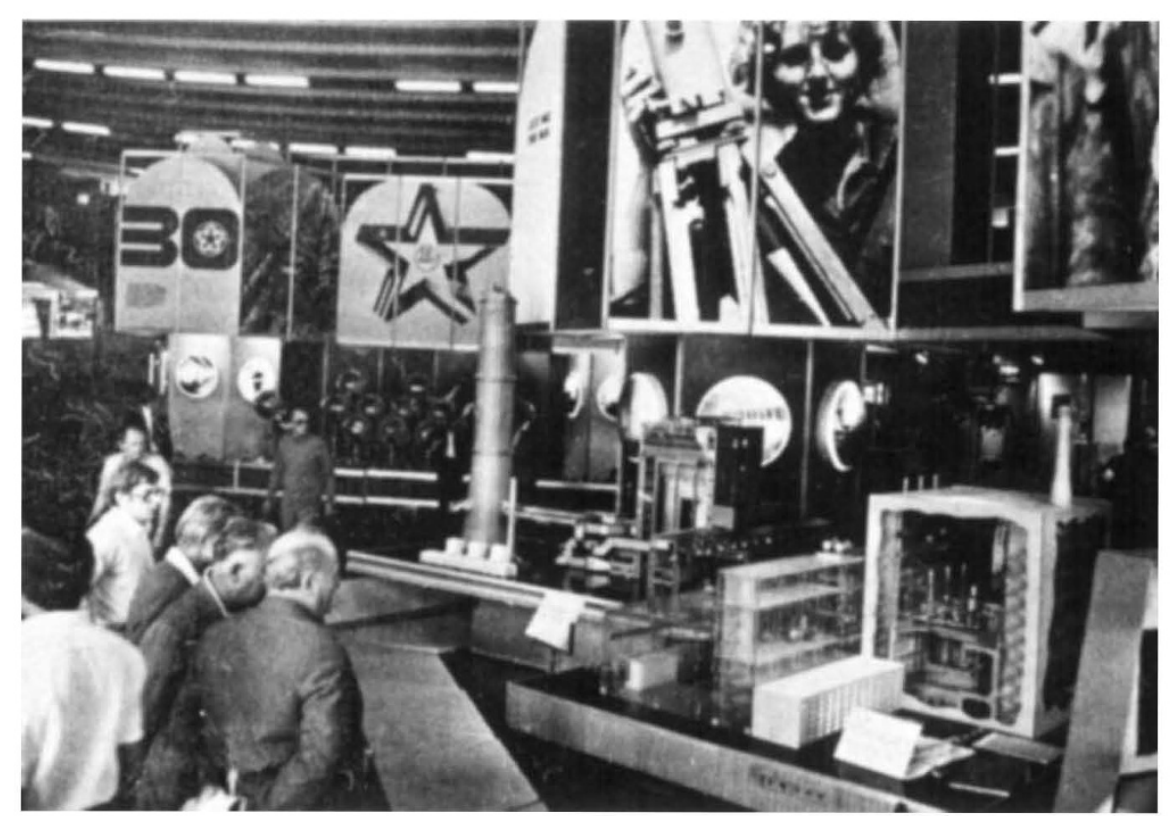

Poznan Fair: only the Poles had their own trading agency

\title{
Selling Polish science
}

THIS year, for the first time, the Polish Ministry of Science, Higher Education and Technology is appearing as an exhibitor in its own right at the Poznan International Fair, under the trading name Posteor; previously only projects developed in universities and polytechnics under its aegis have been on display.

Posteor is a financially autonomous organ of the Ministry of Science, somewhat analogous to the UK National Research Development Corporation. It was set up in 1973, a time when the Academy of Sciences first scrutinised the problems involved in the relationship between research and production. These discussions led to Poland's scheme of graduated 'problems' vital to the economy which are to be solved by science ( 23 November 1978 page 313 ); while, on the administrative side, Posteor was established to handle the implementation of new discoveries and technologies into production.

Implementation is a major problem throughout the Comecon bloc, but only Poland has adopted the idea of a special trading company. Indeed, by working through an existing foreign trading enterprise, Polservice, Posteor can earn valuable hard currency marketing know-how and licences abroad as well as protecting Polish patent rights. Through its exhibition at the Fair, Posteor hopes not only to increase its foreign outlets, but also to sell its technology and expertise at an earlier stage of development. "We can exhibit ideas, pilot technologies and know-how," explained one representative, "even if we haven't ironed out all the snags of full-scale production."

The small selection of projects on display is indeed wide-ranging: it includes a method for producing phosphates as a by- product of sulphuric acid manufacture, and practical expertise in geodesy and water surveying, as well as an analogue system for measuring the field distribution near high voltage power lines - Poland will have its first $350 \mathrm{MW}$ lines next year, as part of the Comecon supergrid. A method of cutting the petrol consumption of the average automobile by $15 \%$ underlines the importance of energy saving in the Posteor exhibits: other examples range from a coldhardening process for worm-drive castings down to a method of freeze-drying whole potatoes. Indeed, energy conservation is a major theme of the entire Polish display, from the generating sets exhibited by Elektrim to the coal-mining pavilion with its placards extolling the leading role of the coal industry.

Following a winter when exceptional weather conditions led to a total halt in production, Poland is now rethinking one aspect of her energy policy, the proposed compensation deal with Austria. Under this agreement, Austria would build hydroelectric generating stations on the Bug, and in return would take two thirds of the current produced for the next 25 years. This scheme - like the proposal for a transCzechoslovakia pipeline to carry coal dust to Austria - is dear to the heart of Austrian trade minister Joesef Staribucker, and such deals are normally popular with the Polish planners because they save hard currency by paying in kind rather than cash. But it is now most unlikely to go through, for, as the Polish viceminister of trade, Edwin Wisniewski, told journalists at the Fair: "Coal and energy are now far too precious for compensation deals. We shall always be willing to sell them, so long as we have them to sell - but it must be strictly for cash." Vera Rich 